\title{
Investigation of Properties of Silk Fiber Produced in Ethiopia
}

\author{
Ayano Koyrita Banale \\ Ethiopian Institute of Textile and Fashion Technology, Bahir Dar University, Bahir Dar, Ethiopia \\ Correspondence should be addressed to Ayano Koyrita Banale; ayubanale@gmail.com
}

Received 27 January 2017; Revised 12 April 2017; Accepted 2 May 2017; Published 28 May 2017

Academic Editor: Tong Lin

Copyright (C) 2017 Ayano Koyrita Banale. This is an open access article distributed under the Creative Commons Attribution License, which permits unrestricted use, distribution, and reproduction in any medium, provided the original work is properly cited.

\begin{abstract}
The atmospheric conditions and other facilities to rear silk filaments are good in Ethiopia. In Awassa, Awash Melkassa, and Kombolcha silk rearing is started with good progress. The quality of the cocoons produced in the country is not determined in relation to commercial silk produced in major silk producing countries. So far there was no information available about the basic properties of silk filaments produced. In this research paper, the different physical properties of the eri and mulberry cocoon and their filaments were evaluated. Eri cocoons have shell ratio of approximately 14\%, average fiber fineness of 3 dtex, and average weight of 3.2-3.3 g, while mulberry cocoons have raw silk ratio of 13-14\%, average fiber fineness of $2 \mathrm{dtex}$, and average weight of $1.5 \mathrm{~g}$. Even though the method of rearing, handling, and harvesting of the cocoons is poor, the physical properties of the silk produced in Ethiopia fall within the limits of commercial silk produced in major silk producing countries.
\end{abstract}

\section{Introduction}

Silk is very soft, lustrous, smooth, strong, and durable than any natural or artificial fiber. The industrial and commercial uses of silk contributed to the silkworm promotion all over the world especially in developing nations [1].

Ethiopia's bimodal rainfall pattern, ambient temperature, and other agro-ecological factors provide a fertile ground for mulberry and caster seed cultivation and silkworm production [2]. Sericulture development of both eri and mulberry silkworms has been introduced into the country very lately. It was initiated by Melkassa Agricultural Research Centre 20 years ago. However, the technology has been disseminated to beneficiaries since 2001. The SNNP Regional Bureau of Agriculture and Rural Development is the first to promote sericulture technology to the rural poor farmers among all the regions. Subsequently related sectors and interested individuals in and around urban areas of Awassa, Nazareth, Addis Ababa, Debrezeit, and Bahir Dar are involved in the development silk production program [2].

According to sericulture training guide report (2005), considerable quantity of dried cocoons, over $3000 \mathrm{~kg}$, was produced both by farmers and investors from which $95 \%$ was marketed to Addis. According to Sabahar yearly report, currently the silk production in Ethiopia has increased by almost 200\% since 2014. Today, Sabahar, the pioneer of local silk, is the only company in the country which produces textiles made of Ethiopian silk for export. Silk products produced in Ethiopia are organic by nature as the plantation for rearing uses natural fertilizers [2].

The favorable conditions of silkworm rearing; rapidly expanding production of silk in the country and the need of organic materials in the world will surely increase the export potential and local utilization of silk. However, so far there are no postcocoon facilities and no information available about the basic properties of silk filaments produced [2-4].

Unless basic properties such as silk fineness, cocoon weight, shell ratio, cleanness, and uniformity are known, it will be impossible to market such silk or even to go ahead for further value addition through reeling and weaving. The success of this work largely depends on characterizing its silk cocoon in terms of fiber properties as well as laying a foundation for further processing such as reeling and twisting.

In this paper, the different physical properties of the eri and mulberry cocoon and their filament were evaluated. Even though the method of rearing, handling, and harvesting of the cocoons is poor, the physical properties of the silk produced in Ethiopia fall within the limits of commercial cocoons produced in major silk producing countries. 


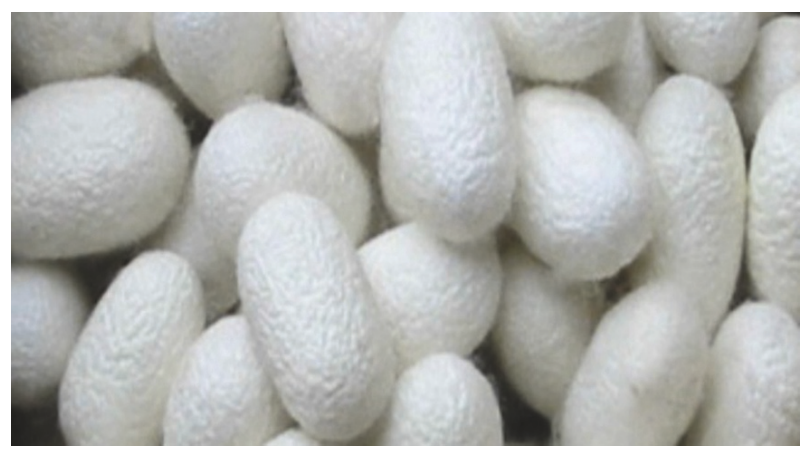

(a)

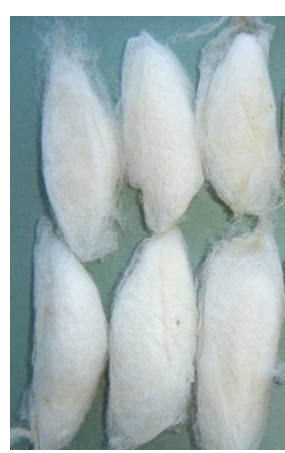

(b)

FIgURE 1: Cocoons: (a) mulberry and (b) eri.

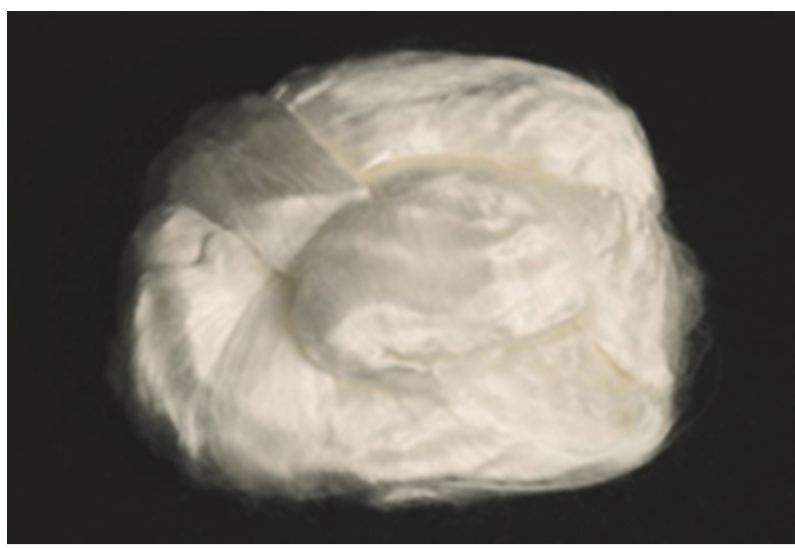

(a)

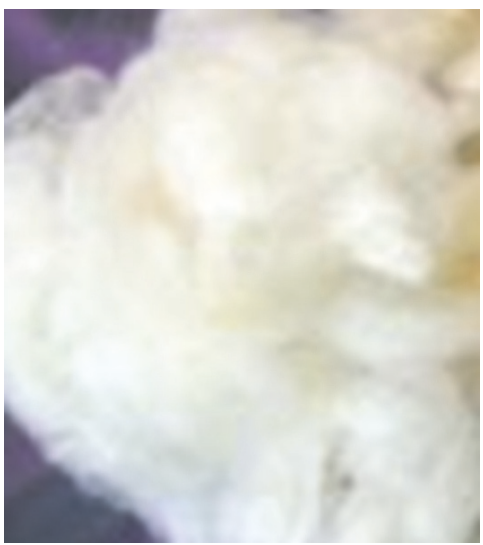

(b)

FIGURE 2: Degummed silk filaments: (a) mulberry and (b) eri.

\section{Materials and Methods}

Samples of eri cocoons were collected from Bahir Dar, Awassa, and Awash Melkassa while samples of mulberry cocoons were collected from Awassa and Awash Melkassa. Longitudinal appearance, silk percentage, fiber fineness, moisture regain, cocoon weight, and quality of cocoons were analyzed using ASTM standard method.

Longitudinal appearance of the filaments was studied under projection microscope with magnification power of $\times 125$ and $\times 250$ with mounting media of liquid paraffin.

Two-pan cooking method was used for reeling by manipulating time and temperature within $45-98^{\circ} \mathrm{C}$. Alkali gum removal method was used to degum the filaments. $5 \%$ sodium carbonate, 1:20 material to liquor ratio, $98^{\circ} \mathrm{C}$ temperature of cooking, and 2 hours of degumming were used during degumming.

Weight of cocoons, shell, and degummed filaments was measured using electronic weighing balance and appropriate proportions were calculated. Broken filaments were taken from outer layer; filaments were degummed and their linear density was measured on vibroscope (fineness testing machine) with appropriate loads of $200 \mathrm{mg}-400 \mathrm{mg}$ for eri silk, while for mulberry silk the filament of $25 \mathrm{~m}$ length was taken on the outer layer during reeling. Filaments were degummed and weighed. Linear density was calculated.

Moisture content of the fiber was analyzed by SDL Rapid Regain Tester and weighing balance. Ten samples, each weighing $10 \mathrm{gm}$, were prepared from each type and origin. The oven was heated until the temperature rose to $105^{\circ} \mathrm{C}$. One sample was inserted in the oven and its weight was measured after 25 minutes. This was done repeatedly till the weight loss is less than $0.05 \%$. This is taken as dried sample and moisture content was measured.

Sorting of quality cocoons was made by observation. During observation the quality of dirty/impurities, degree of whiteness, size of the cocoon, and hardness of the cocoon were taken into consideration. Those cocoons with defects and with fewer defects are differentiated.

\section{Results and Discussions}

3.1. Shape and Appearance. When fiber is observed under microscope it is smooth in surface and profile, and sometimes nodes appear. The eri filament is more irregular than mulberry silk. Undegummed eri cocoons are grey, while mulberry silk varies from grey to yellow as shown in Figures 1 and 2. However, degummed fibers were brighter than the undegummed for both varieties. 
TABLE 1: Shell percentage of eri cocoon.

\begin{tabular}{lccc}
\hline Sample of eri silk & Cocoon weight $(\mathrm{gm})$ & Shell weight $(\mathrm{gm})$ & Shell percentage $(\%)$ \\
\hline Awash Melkassa & 200.8 & 29.5 & 14.2 \\
Bahir Dar & 200.2 & 26.8 & 13.4 \\
Awassa & 201.0 & 27.7 & 13.7 \\
\hline
\end{tabular}

TABLE 2: Silk percentage of mulberry cocoons.

\begin{tabular}{lccc}
\hline Sample of cocoon & Cocoon weight $(\mathrm{gm})$ & Weight of filament $(\mathrm{gm})$ & Raw silk percentage $(\%)$ \\
\hline Awash Melkassa & 68.3 & 9.7 & $14.2 \%$ \\
Awassa & 36.4 & 4.5 & $12.9 \%$ \\
\hline
\end{tabular}

3.2. Silk Percentage. 10 samples, each weighing nearly 200 grams, were prepared; pupa was separated from the cocoons and shell weight was measured for eri cocoons. Mulberry cocoons were degummed after reeling. Average weights of cocoon, shell, and raw silk were taken as shown in Tables 1 and 2.

As can be seen from Tables 1 and 2 the shell percentage of eri cocoons is approximately $14 \%$ for all the places while raw silk percentage of mulberry is bout $13-14 \%$. The raw silk percentage of mulberry from Awash Melkassa is higher than from Awassa.

Raw silk ratio varies with breed of silk worms and care taken in rearing and mounting. It also varies with the age of cocoons. The trend observed by K. Subramanianan, N. Sakthivel, and S. M. H. Qadri shows that South Indian eri cocoons shell percentage ranges from 10 to $15 \%$ [5]. Raw silk percentage of mulberry is $7-10 \%$ for multivoltine cocoons, $11-15 \%$ for bivoltine cocoons, $16-19 \%$ in newly evolved hybrids, and $19-25 \%$ in Japanese reeling cocoons [6-8]. This indicates that the shell percentage of Ethiopian eri cocoons is in the range of good quality South Indian cocoons, while mulberry cocoons silk ratio falls in the range of bivoltine cocoons.

3.3. Fiber Fineness. Broken filaments were taken from the outer layer of eri cocoons and linear density was measured on vibroscope after degumming. The filament of $25 \mathrm{~m}$ length was taken from outer layer of mulberry cocoons during reeling. Filaments were degummed and weighed. Linear density of the filaments was calculated. The distribution of linear density in dtex is shown in Figures 3 and 4.

The fiber fineness distribution of eri and mulberry cocoons of all places is shown in smoothened curves in Figures 3 and 4 . The mean value of the fiber fineness for eri silk is 3.09 dtex from Bahir Dar, 2.91 dtex from Awassa, and 3.11 dtex from Awash Melkassa with standard deviations of $0.32,0.29$, and 0.25 , respectively, while fineness for mulberry silk is $2.1 \mathrm{dtex}$ from Awassa and 2.4 dtex from Awash Melkassa with standard deviations of 0.05 and 0.12 , respectively. The eri filament from Awassa is found to be finer as compared to Bahir Dar's and Awash Melkassa's filaments. Mulberry filament is finer than eri filaments.

Silk worm varieties are many and the filaments they produce are also diverse in characteristics. Even in the same species, the filaments they produce vary because the

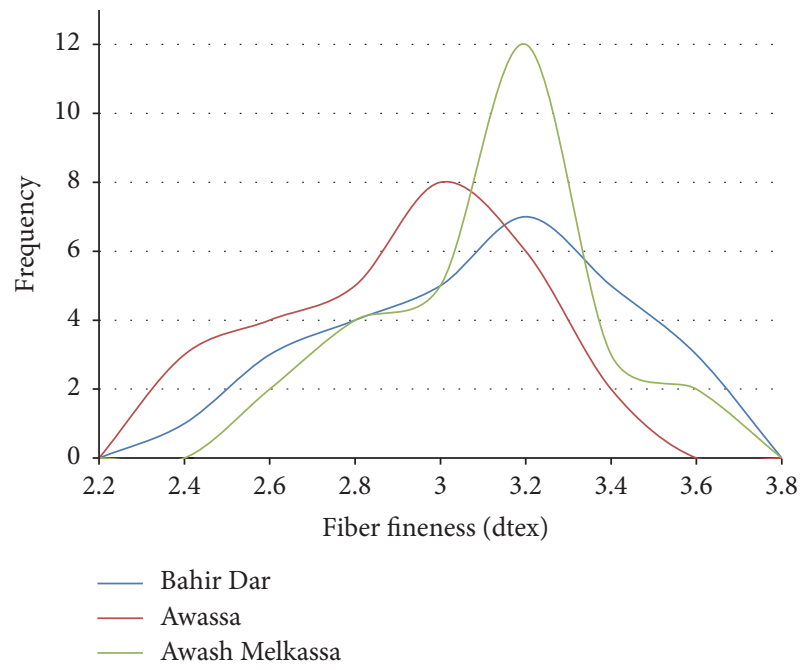

FIGURE 3: Fiber fineness distribution in dtex of eri silk from Bahir Daar, Awassa, and Awash Melkassa.

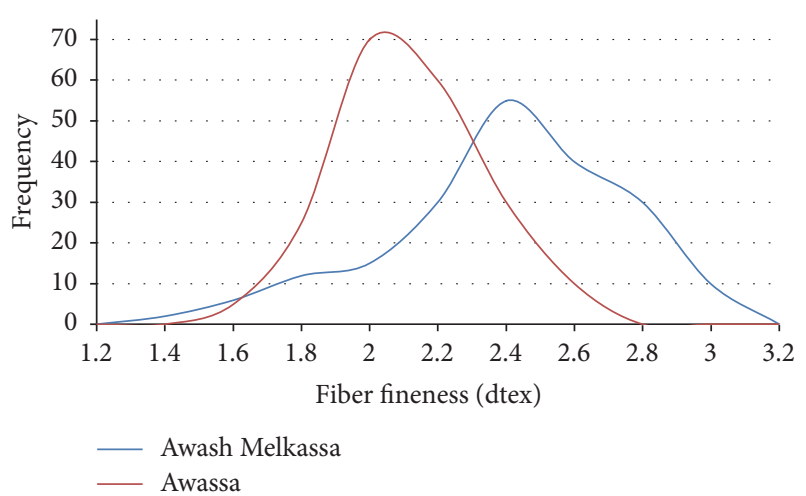

Figure 4: Fiber fineness distribution in dtex of mulberry silk from Awassa and Awash Melkassa (note: frequency: number of times it has occurred).

environmental conditions and the host plant they could use are different. Fineness of silk fiber varies from 1 dtex to 5 dtex depending on type and place of fibers, while eri and mulberry silk takes fineness ranges of 1 dtex to 3 dtex [9-11].

3.4. Weight of Cocoon. Sample of cocoons was randomly selected for all types of cocoons. Individual cocoons of the 
TABLE 3: Percent moisture regain of the various silk types.

\begin{tabular}{lcccc}
\hline Fiber type & Origin & Initial weight $(\mathrm{g})$ & Average final constant weight $(\mathrm{g})$ & \% regain \\
\hline \multirow{3}{*}{ Eri silk } & Awassa & 10.00 & 9.05 & 10.50 \\
& Bahir Dar & 10.00 & 9.10 & 9.93 \\
& Awash Melkassa & 10.00 & 9.15 & 9.79 \\
\hline \multirow{2}{*}{ Mulbery } & Awasa & 10.00 & 9.30 & 8.50 \\
& Awash Melkassa & 10.00 & 9.25 & 9.10 \\
\hline
\end{tabular}

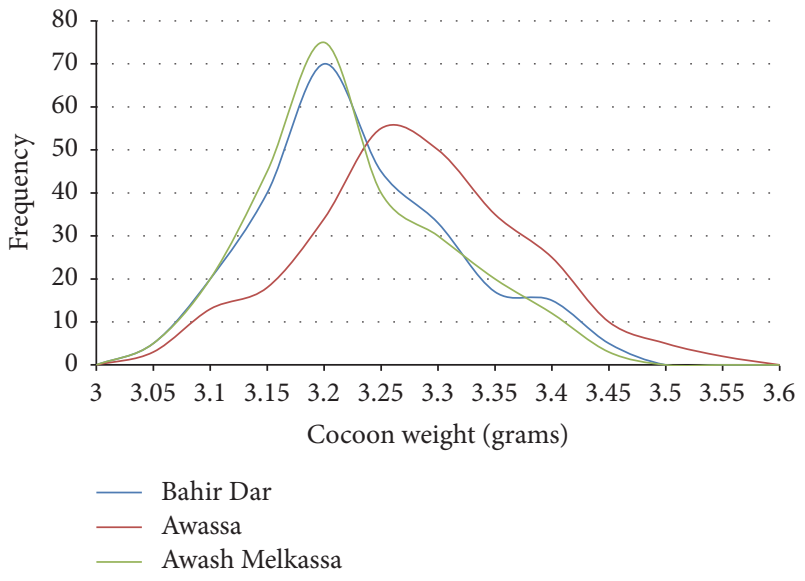

FIGURE 5: Distribution of cocoon weight in grams for eri silk fiber from Bahir Dar, Awassa, and Awash Melkassa.

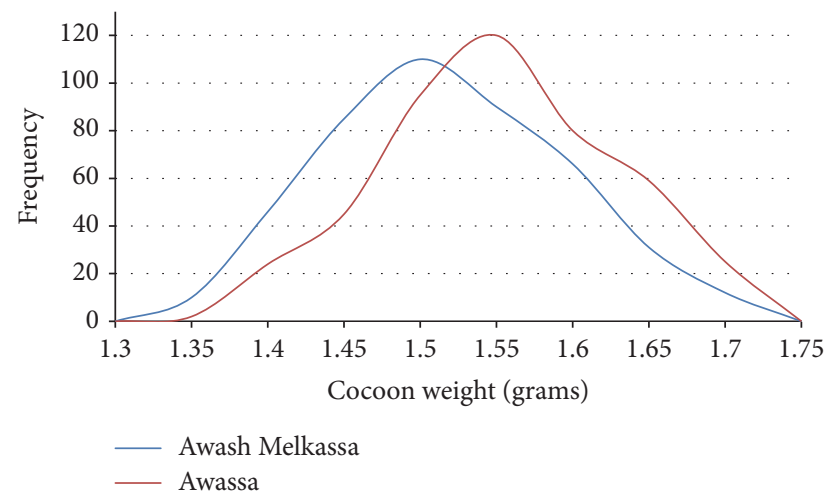

FIgURE 6: Distribution of cocoon weight in grams for mulberry silk fiber from Awassa and Awash Melkassa.

samples selected were weighed on precision weighing balance in grams. The distribution of cocoon weight is given in Figures 5 and 6.

Figure 5 and 6 indicate that the mean cocoon weight of eri silk is $3.23 \mathrm{~g}$ for Bahir Dar, $3.28 \mathrm{~g}$ for Awassa, and $3.22 \mathrm{~g}$ for Awash Melkassa, while cocoon weight of mulberry silk is $1.55 \mathrm{~g}$ for Awassa and $1.52 \mathrm{~g}$ for Awash Melkassa. This shows that there is no significant difference in cocoon weight of the same type but eri silk cocoons have higher weight than mulberry cocoons.

Cocoon weight of pure breed mulberry varies from 1.5 to $2 \mathrm{~g}$. Eri silk produced in major silk producing countries varies from 2.5 to 3.5 [12-15]. This clearly indicates that the weight of eri cocoons in these places is in the upper limit of the commercial silk produced in major silk producing countries while mulberry silk falls within the pure breeds. Even though the sericulture is not scientifically applied cocoon weight is in the normal range of commercial silk produced in major producing countries.

3.5. Moisture Absorption. Cocoons were degummed before moisture analysis. Ten samples of degummed fibers from each type and origin were prepared. Each sample was heated repeatedly in oven dryer till the weight loss is less than a difference of $0.05 \%$. Average value of the regain percentage is given for each type of samples as shown in Table 3.

The moisture regain at standard conditions of eri silk was approximately $10 \%$ while mulberry silk was approximately $9 \%[16,17]$.

Mulberry raw silk fiber has a moisture regain of $11 \%$, which reduces to about $9 \%$ after degumming (at standard atmospheric conditions, $27^{\circ} \mathrm{C}$ and $65 \% \mathrm{RH}$ ). This is due to the removal of much hygroscopic sericin from the raw silk fiber during the degumming process. Eri silk fibers have about 10\% moisture regain values $[18,19]$.

3.6. Quality of the Cocoons by Sorting. 200 gram of cocoon was randomly taken for all types of cocoons. Sorting by manual observation, good quality cocoon and poor quality cocoons were identified. Any defected cocoons, having difference in color, or being smaller in size were considered as poor cocoons. By measuring the sorted samples percentage values were obtained. This was made five times and average values of good and poor quality cocoons were calculated as shown in Table 4.

As per the guidelines of sorting given, Table 4 indicates that more than $60 \%$ of the cocoons observed are good.

The poor quality cocoons could be due to the weak method of rearing, handling, and harvesting of the cocoons in these harvesting areas. All the places use traditional houses for rearing and simple wooden/timber/frames with corn stalk ribs for rearing stages in uncontrolled conditions. They also do not follow a regular leaves feeding but rather provide leaves to worms irregularly. Feed efficiency affects quality of cocoons produced.

\section{Conclusion}

Even though the method of rearing, handling, and harvesting of the cocoons is poor, the quality of cocoons produced in Ethiopia is in the range of commercial silk produced in 
TABLE 4: Percentage of good quality cocoons for the various types of cocoons.

\begin{tabular}{lcr}
\hline Fiber type & Origin & Good quality cocoons in \% \\
\hline \multirow{2}{*}{ Eri silk } & Bahir Dar & 52 \\
& Awassa & 64 \\
\hline \multirow{2}{*}{ Mulberry silk } & Awash Melkassa & 60 \\
& Awassa & 68 \\
\hline
\end{tabular}

major silk producing countries. The shell percentage of eri cocoons is nearly $14 \%$ for all the places, while raw silk ratio of mulberry is bout $13-14 \%$. The mean value of the fiber fineness for eri silk is 3.09 dtex from Bahir Dar, 2.91 dtex from Awassa, and 3.11 dtex from Awash Melkassa, while fineness for mulberry silk is $2.1 \mathrm{dtex}$ from Awassa and $2.4 \mathrm{dtex}$ from Awash Melkassa. The mean cocoon weight of eri silk is $3.23 \mathrm{~g}$ for Bahir Dar, $3.28 \mathrm{~g}$ for Awassa, and $3.22 \mathrm{~g}$ for Awash Melkassa cocoons while cocoon weight of mulberry silk is $1.55 \mathrm{~g}$ for Awassa and $1.52 \mathrm{~g}$ for Awash Melkassa cocoons. More than $60 \%$ of the cocoons observed are good. If proper rearing and handling of cocoons are used, it is possible to produce higher quality cocoons.

\section{Conflicts of Interest}

The authors declare that they have no conflicts of interest.

\section{References}

[1] K. Shifa, W. Sori, and E. Getu, "Feed Utilization Efficiency of Eri-Silkworm (Samia cynthia ricini Boisduval) (Lepidoptera: Saturniidae) on Eight Castor (Ricinus communis L.) Genotypes," International Journal of Innovative and Applied Research, vol. 2, no. 4, pp. 26-33, 2014.

[2] K. Shifa and Y. Nobuak, Sericulture training guide, Gezahegn Tadesse- Ministry of Agriculture ¿amp; Rural Development (MARD), Metaferia H/Yimer-Ethiopian Agricultural Research Organization (EARO), Japan International Cooperation Agency (JICA), Addis Ababa, Ethiopia, 2005.

[3] Sericulture in, JAICAF, East Africa, March 2007.

[4] A. A. Weldeyohannes, "Silkworm Production and Constraints in Eastern Tigray," International Journal of Innovation and Scientific Research, vol. 10, no. 2, pp. 517-521, 2014.

[5] K. Subramanianan, N. Sakthivel, and S. m. H. Qadri, "Rearing technology of eri silkworm (Samia Cynthia Ricini) under varied seasonal and host plant conditions in Tamil Nadu," International Journal of Life Sciences Biotechnology and Pharma Research, vol. 2, no. 2.

[6] T. N. Sonwalkar, Hand Book of Silk Technology, 2001, Hand book of silk technology, Sonwalkar, Tammanna N,.

[7] D. Brahma, A. Swargiary, and B. Dutta, "A comparative study on morphology and rearing performance of Samia ricini and Samia canningi crossbreed with reference to different food plants," Journal of Entomology and Zoology Studies, vol. 3, no. 5, pp. 1219, 2015.

[8] S. Chanda, L. M. Saha, N. K. Das, N. B. Kar, and B. B. Bindroo, "Correlation among Shell Percent, Cocoon Yield and Reeling
Parameters of Multi $\times \mathrm{Bi}$ Cocoons under Different AgroClimatic Conditions of West Bengal," International Journal of Industrial Entomology, vol. 26, no. 2, pp. 74-80, 2013.

[9] K. M. Babu, Silk Processing, Properties and Applications, 2013.

[10] C. A. Lawrence, Fundamentals of Spun Yarn Technology, 2002.

[11] V. B. Gupta, R. Rajkhowa, and V. K. Kothari, "Physical characteristics and structure of indian silk fibers," Indian Journal of fiber and Textile Research, vol. 25, pp. 14-19, 2000.

[12] M. Lewin, Hand Book of Fiber Science and Technology, vol. 4, 1995.

[13] K. Subramanian, N. sakthivel, and s. m. h. Qadri, "Effect of cocoon characters, copulation and oviposition devices on the grainage performance of samia Cynthia ricinisciences biotechnology and pharma research," International Journal of Life Sciences Biotechnology And Pharma Research Hyderabad, vol. 1, no. 4.

[14] P. Sharma and J. C. Kalita, "A comparative study on six strains of eri silk worm (samia ricini; donovan) based on morphological traits," Global Journal of Bio-Science and Biotechnology, vol. 2, no. 4,2013

[15] K. Subramanian, N. Sakthivel, and S. M. H. Qadri, "Effect of cocoon characters, copulation and oviposition devices on the grainage performance of samia cynthia ricini (boisduval)," International journal of life science and pharma research, vol. 1, no. $4,2012$.

[16] K. Shifa, E. Getu, and W. Sori, "Rearing performance of eri-silkworm (Samia cynthia ricini Boisduval) (Lepidoptera: Saturniidae) fed with different castor (Ricinus communis L.) genotypes," Journal of Entomology, vol. 11, no. 1, pp. 25-33, 2014.

[17] H. Argua, Principles of Sericulture translated from Japanese, 1994.

[18] A. Basu, Ed., Advances in Silk Science and Technology, The textile Institute, 2015.

[19] A. Teshome, S. K. Raina, F. Vollrath, J. M. Kabaru, J. Onyari, and E. K. Nguku, "Study on weight loss and moisture regain of silk cocoon shells and degummed fibers from African wild silkmoths," Journal of Entomology, vol. 8, no. 5, pp. 450-458, 2011. 

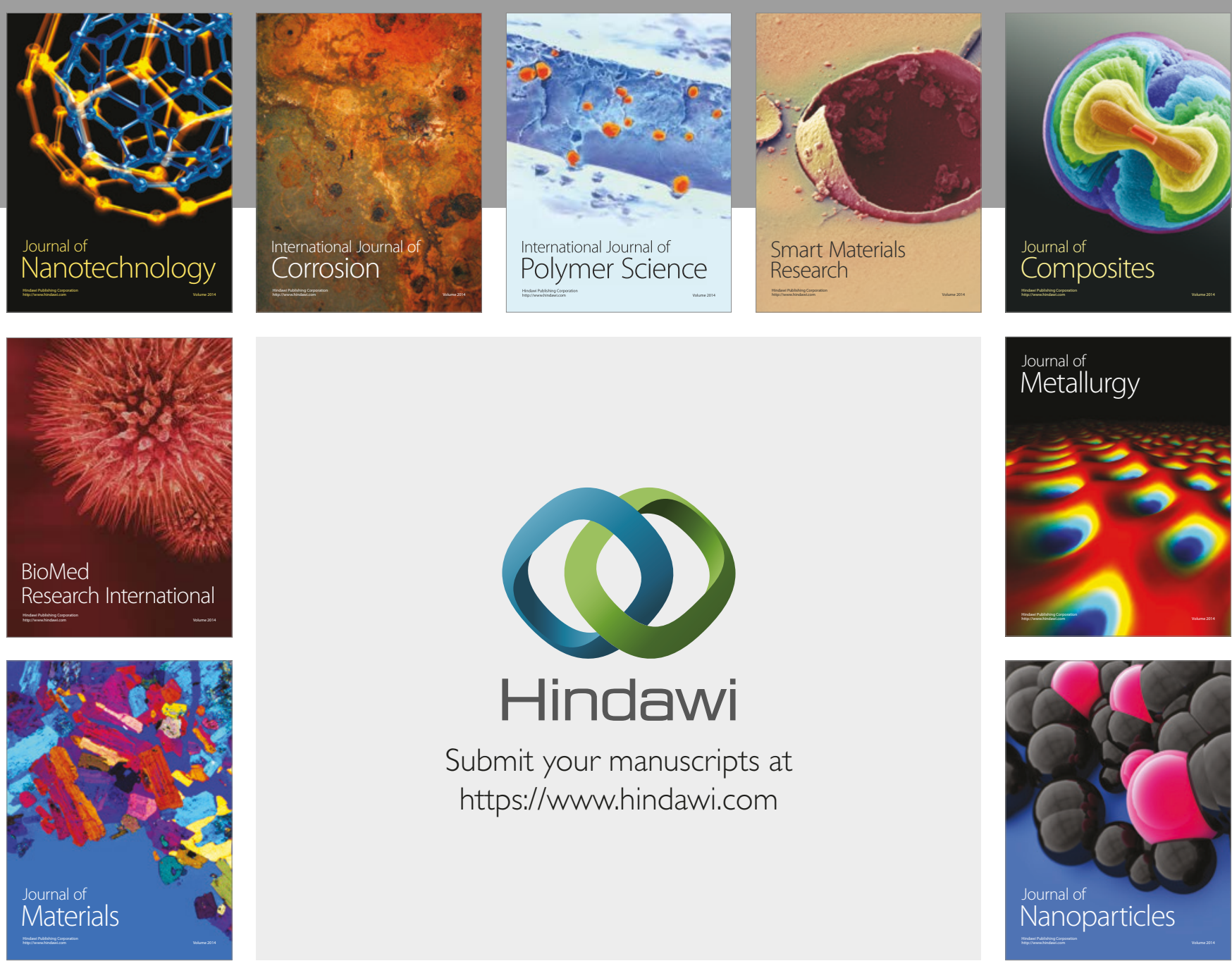

\section{Hindawi}

Submit your manuscripts at

https://www.hindawi.com
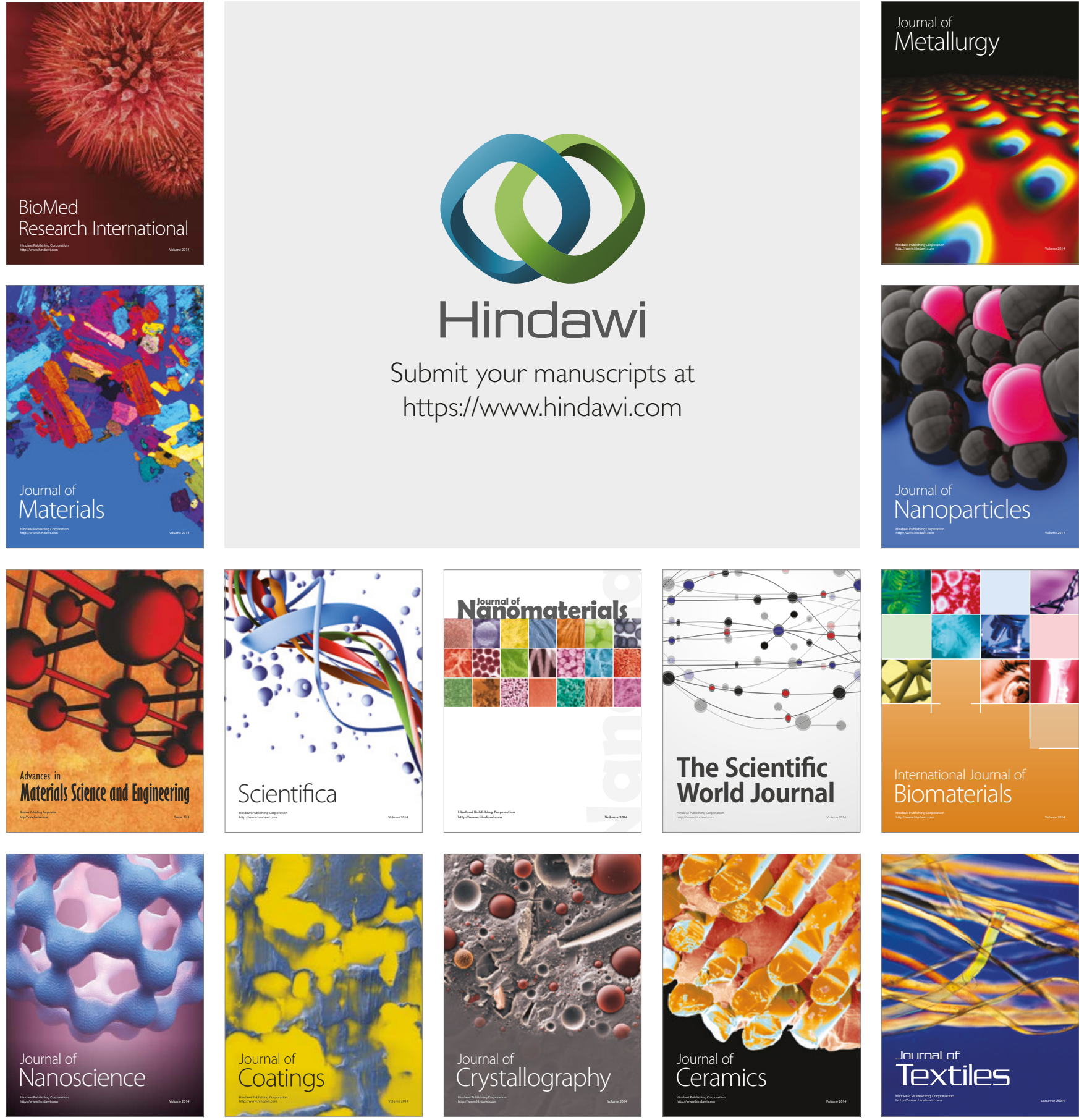

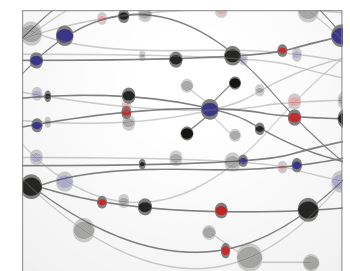

The Scientific World Journal
